\title{
Disciplina Interprofissional em Saúde: Avaliação por meio de portfólio reflexivo
}

\author{
Najara Rocha, Adriana Lenita, Miriam Leiko Terabe, Adriana de Sant'ana Gasquez, Kathiussa \\ Fernanda Parreira Rodrigues
}

\begin{abstract}
Resumo
Introdução: A disciplina de Atenção em Saúde I envolve os estudantes de Medicina, Enfermagem, Odontologia, Psicologia, Farmácia, Biomedicina e Educação Física da Universidade Estadual de Maringá (UEM). Uma proposta pioneira, que integra 7 profissões com o objetivo de promover a educação interprofissional e de estimular as práticas colaborativas em saúde por meio da problematização, tendo como cenários de ensino as Unidades Básicas de Saúde (UBS), do município de Maringá- PR. Grupos de até 10 alunos, sendo pelo menos 1 de cada curso, desenvolvem suas atividades. Objetivos: Apresentar o portfólio reflexivo como instrumento de avaliação de disciplina interprofissional. Métodos: A análise conceitual de portfólio reflexivo permitiu que o mesmo fosse adotado como referencial de avaliação da disciplina em tela. Para isso os estudantes foram orientados a construí-lo. Resultado/Discussão: sendo uma ferramenta importante da formação por competências e da avaliação formativa, o portfólio deve permear as habilidades cognitivas, tecnológicas, instrumentais, sociais e afetivas. $O$ tutor estimulou os estudantes a registrar as idéias e argumentações embasadas na pesquisa científica, bem como nas respostas as diferentes situações vivenciadas nos cenários de prática, observando diferenças comportamentais, cognitivas, estilos e tempos de aprendizagem. Cabe destacar alguns registros como, por exemplo: “...Uma das experiências mais marcantes para mim foi o dia em que fizemos a visita domiciliar com a ACS Fátima. Ver como a realidade de algumas pessoas destoa da minha foi uma experiência que me fez crescer e querer mudar esta realidade". Ou ainda: “...Na lei o SUS aparenta ser de primeiro mundo, todavia há muito a ser feito e cobrado dos gestores públicos, vejo nesta disciplina um dos passos para esta mudança tão necessária”. Conclusão: O portfólio reflexivo apontou ser instrumento importante de aprendizado e permitiu valorizar as condutas e discussões que promovam o respeito entre as profissões envolvidas, a ética, estimulando o trabalho colaborativo.
\end{abstract}

Descritores: Educação, Avaliação, Ética, Serviço de Saúde, Currículo 